www.jmscr.igmpublication.org

Impact Factor 5.84

Index Copernicus Value: 83.27

ISSN (e)-2347-176x ISSN (p) 2455-0450

crossref DOI: https://dx.doi.org/10.18535/jmscr/v5i7.181

Journal Of Medical Science And Clinical Research

IGM Publication

An official Publication of IGM Publication

\title{
Evaluating Foleys Balloon Catheter Tamponade in Non -Traumatic Postpartum Haemorrhage Resistant to Medical Management and Preventing Unwanted Hysterectomy
}

\author{
Authors \\ Dr A. Rajeswari* , Dr P. Chithra
}

*Head, Dept of Obstetrics and Gynaecology, Govt Vellore Medical College, Vellore, Tamilnadu, India

\begin{abstract}
Background: Obstetric haemorrhage remains the most important cause of maternal mortality worldwide accounting for $25 \%$ of maternal deaths annually. The aim of the study was to evaluate efficacy of a foleys balloon catheter assembly for uterine tamponade in the management of non-traumatic postpartum haemorrhage (PPH).

Methods: It is a prospective interventional study done in a tertiary care hospital in Tamilnadu state, Vellore district, Government Vellore Medical college Adukkamparai, India.. 145 women with intractable PPH unresponsive to medical management are managed by intrauterine Foleys balloon tamponade using a foleycatheter assembly prior to surgical intervention.

Results: The Foleys balloon catheter tamponade successfully controlled haemorrhage in131 out of 145 patients. It is observed that among the 12 failed cases, hysterectomy was required. Further the cases were managed by doing bilateral internal iliac artery ligation. Among the failed cases there was a one maternal death due to sepsis and multi-organ dysfunction syndrome(MODS). It is also observed that in all cases where the balloon was successful, it was removed around 24 hours later and no further bleeding or complication was noted.

Conclusions: Placement of a Foleys catheter balloon tamponade can successfully treat non-traumatic PPH refractory to medical management. It is simple, inexpensive, easily available and in those with successful placement no procedure related morbidity was observed. The potential for this method is it can be used inexperienced operators in areas with limited resources and makes it a useful tool in management of PPH.

Keywords: Postpartum haemorrhage, Condom catheter balloon, Non-traumatic.
\end{abstract}

\section{INTRODUCTION}

Obstetric haemorrhage remains the most important cause of maternal mortality worldwide accounting for $25 \%$ of maternal deaths annually. It is estimated that worldwide one woman dies every four minutes due to postpartum haemorrhage with an average yearly incidence of about 1,40,000 women deaths .One of the numerous causes of postpartum haemorrhage, uterine atony is the commonest, complicating 1 in 20 pregnancies. However, death from PPH can largely be avoided through proper prevention, diagnosis and management. $^{2}$ Doumouchtsis SK et al in a systematic review to identify all the studies evaluated the success rates of treatment of PPH with uterine balloon tamponade, uterine 
compression sutures, pelvic devascularisatiuon and arterial embolization. ${ }^{3}$ The cumulative outcomes showed success rates of $84 \%$ (95\% CI, $77.5 \%-88.80 \%$ ) for balloon tamponade. It was concluded that Foleys balloon tamponade was the least invasive and most rapid remedy for PPH management and should be considered as the first step following failure of medical therapy.

Foleys balloon catheter is a cheap and easily available alternative to catheters like sengstaken Blakemore tube and foleys catheter balloon which are commonly used for tamponade in post-partum haemorrhage. This prospective study was planned to evaluate the utility and effectiveness of foleys catheter tamponade in non-traumatic PPH after failure if medical management

\section{AN IDEAL MANAGEMENT OPTION WOULD}

- Easily administered and removed.

- Control capillary / venous bleeding and surface oozing

- Gauge success of treatment in real time.

- Avoid hysterectomy and to preserve the patient's reproductive potential.

VARIOUS MANAGEMENT MEASURES ARE USED TO CONTROL BLEEDING

- Uterotonics

- Packing

- Manual compression

- Embolisation

- Laprotomy

- Hysterectomy

Severe bleeding is the single most significant cause of maternal death worldwide. More than half of all maternal deaths occur within 24 hours of delivery, because of excessive bleeding. In the present study the main aim to control the bleeding using the above said ideal management options.

\section{DISSCUSSION}

Postpartum hemorrhage (PPH) is defined as bleeding that occurs immediately after the placental delivery with an estimated blood loss of more than 500ml. An additional definition for
PPH after caesarean delivery arbitrarily refers to blood loss of over $1000 \mathrm{ml}$. First line treatment options for PPH include conservative management with Uterotonics drugs (oxytocin or prostaglandin, per rectal misoprostol methergine); second line of therapy includes, external compression with uterine sutures and selective devascularisation by ligation or Embolisation of uterine artery. Failure of conservative management is often deemed to warrant hysterectomy, which may be associated with further blood loss and additional morbidity. Although the use of Uterotonics drugs and various conservative measures are included in various authoritative protocols, the actual utilisation rates and timing of these procedures vary widely from centre to centre. In our study intrauterine foleys catheter balloon tamponade has been quite widely used as a second line procedure in the management of massive PPH, and has become an integral part of the HEMOSTASIS management algorithm widely advocated in the UK. Various type of balloon catheter have been reported in literature, including Bakri balloon, the Rush balloon, the Sengstaken-Blakemoore tube or FOLEY catheter adapted for intrauterine tamponade. The current case series describes its use in management of massive PPH that continued despite medical therapy. PPH remains in the top five causes of maternal death in both developed and developing countries.PPH is an emergent situation .The decision for appropriate treatment must be made in a matter of minutes .Proper treatment of PPH is multifactorial and can range from simple options to complex treatment. Patients with PPH can deteriorate very quickly.

Currently the intrauterine balloon is believed to act by exerting in inward-to-outward pressure 'that is greater than the arterial pressure' to prevent continual bleeding. More recently an alternative mechanism of action has been proposed, which involves the hydrostatic pressure effect of the balloon on the uterine arteries.

Many of these balloons have previously been used to control hemorrhage at other anatomical sites, 
including the bladder and oesophagus, as well as to control PPH from vaginal laceration.

Tindell $\mathrm{K}$ et al conducted a systematic analysis to evaluate the effectiveness of various types of uterine balloon tamponade including Foleys catheter, Sengstaken Blakemore and oesophageal catheter.

Rathore AM et al in their prospective study conducted from 2009 to 2012 at Maulana Azad Medical College New Delhi, India, evaluated the effectiveness of condom catheter tamopnade in the management of nontramatic PPH resistent to medical management. In the present study the time taken to arrest the bleeding after the application of Foleys tamponade was 5 to 10 minutes which was comparable to the study by Rathre AM et al. .While waiting for the arrest of hemorrhage simultaneous arrangements can be done to proceed surgical measures, .So waiting for 10 to 15 minutes for the heomrrhage to stop while patient and preparing the theatre for laprtotomy can be justified when weighed against radical procedure like hysterectomy..Hence guarded wait can prevent radical procedures like hystectomy more importantly in primiparus women.

Average blood loss per patient in the present study due to $\mathrm{PPH}$ was $500 \mathrm{ml}$ to 1.5 litres. All 141 patients were transfused with adequate blood products..Average blood products transfused were 3 units of whole blood 4 units of FFP and 2 units of platelets. The mean duration of hospital stay was 7 to 9 days .All the cases were followed up at 6 weeks postpartum. None of them had any clinical signs and symptoms of endometrities. Among 15 cases in whom Foleys tampnade failed were taken up for emergency laprotomy and proceeded with hysterectomy. In three cases simultaneous bilateral internal iliac artery ligation was done to control the bleeding.

Furthermore, these same technologies have been used in gynaecological conditions in which bleeding is problematic. For example following first and second trimester termination of pregnancy, cervical pregnancy, knife cone biopsy, laser ablation of endometrium, dysfunctional uterine bleeding, multiple vaginal lacerations and bleeding from a cervical stump following a post caesarean section subtotal hysterectomy

\section{METHODS}

In the present study all women with postpartum hemorrhage, who were admitted in hospital were included.. The recruited women were screened including the age, parity, gestational age, mode of delivery, duration of delivery, singleton, multiple gestational births, place of delivery. A physical examination was done. Vitals pulse rate, pulse volume, blood pressure, SPO2, urine output respiratory rate, temperature were recorded. Rapid systemic examination, per abdominal examination, per vaginal examination was done to assess the amount of blood loss and rule out traumatic causes of PPH., Transabdominal ultrasound examination was done to assess the uterine cavity. Blood Hemogram PCV. Blood grouping typing, cross matching, Elecrolytes, urea creatinine coagulation profile and urine investigations were also done. Ensuring that atonicity was the cause for PPH utrerotonic drugs were administered as primary management. Inspite of the primary utrerotonic management and adequate blood products replacement if the blood loss continued Foleys balloon intrauterine tamponade was tried in our study.

\section{FOLEY CATHETERS}

Both single and multiple foley catheters have been used in the management of PPH. They were inflated with $60 \mathrm{ml}$ normal saline to achieve haemostasis and patients were monitored in the intensive units with vitals charts and adequate blood and blood products replacement. and subsequently removed after 24 hours without further bleeding. Monitoring of vital signs and intravenous access were continued. Record of pulse rate, blood pressure, heart rate ,Respiratory rate SPO2, Temperature hourly urine output, were monitored. 


\section{CLINICAL}

TAMPONADE TEST

Various descriptions describe filling the balloons until bleeding is controlled. This tamponade test is considered 'POSITIVE' if control is achieved following inflation of balloon. Although this test was originally coined with reference to using the Sengestaken - Blackmore tube it is equally applicable for any of the balloons. The tamponade test serves to formalise the stages of managing the PPH as a 'NEGATIVE' tamponade test control of PPH not achieved following inflation of the balloon suggests that further management, such as laprotomy or an early course of hysterectomy is necessary.

The Foleys intrauterine balloon catheter was the only intrauterine balloon device available in our department. A retrospective review of all cases worth severe PPH following delivery in our unit during the 1 year period from Jan 2016 to Dec 2016 performed, based on a comprehensive obstetric database currently in use in all HA obstetric units.

The case notes of each of these patients were reviewed manually to verify whether intrauterine balloon tamponade techniques had been used in their management. All identified cases where intrauterine balloon tamponade had been used or attempted were then reviewed in detail for the mode of delivery intrapartum complications. Information was also retrieved about the cause of the $\mathrm{PPH}$, the sequence of treatments, estimated total blood loss, any complications resulting from different therapeutic manoeuvres and clinical outcomes. The relevant international literature was then reviewed to compare our results with those of other using intrauterine balloon tamponade for same purpose.

The procedure for insertion of the foley balloon into the intrauterine cavity was similar to that originally described by the inventor though vaginal packing was not routinely performed unless there was evidence of slippage or prolapsed of balloon through the cervix. The distal end of the catheter was connected to the routine urobag to measure the amount the blood loss. . While ultrasound visualisation of balloon placement was reported in the literature this was not considered necessary in our series .when the balloon was inserted during caesarean section, the distal end of the balloon shaft was passed through the cervical opening with an assistant pulling the end per vagina and connected to the routine urobag to assess the blood loss. The use of a traction sutures to keep the balloon in the uterus was not undertaken. If bleeding was arrested after balloon inflation the balloon tamponade was continued for 24 hours after which the deflation was performed either in two stages or in a single stage (depending on attending obstetrician's discretion). All patients had an indwelling foley catheter to monitor urine output and broad spectrum antibiotics were used for prophylaxis.

\section{RESULTS}

In the present study from Jan 2016 to Dec 2016 there were 10393 deliveries over review period During this study period we had 146 case of PPH due to uterine atonicity were analysed .The main cause for atonicity were Anemia ,over distended uterus that included \{Polyhydramnios, macrosmia\}, multiple gestational pregnancies. ,preeclampsia, prlonged labour, Grand multipara. Among the 146 patients with massive PPH there were 131 patients in whom the foley balloon catheter intra uterine tamponade was used and we were able to control.and conserve the patients uterus. Within the same period there were 15 peripartum hysterectomies due to continuing blood loss. Out of this 15 peripartum hysterectomies there was one maternal death due multiorgan failure.

\begin{tabular}{|l|c|c|c|l|l|}
\hline S.NO & CAUSE OF PPH. & $\begin{array}{c}\text { NO OF } \\
\text { CASES. }\end{array}$ & $\begin{array}{c}\text { TOTAL } \\
\text { CASES } \\
\text { OF PPH }\end{array}$ & & \\
\hline 1 & Anemia. & 35 & & & \\
\hline 2 & PREECLAMPSIA. & 29 & & & \\
\hline 3 & $\begin{array}{c}\text { OVER DISTENED } \\
\text { UTERUS. }\end{array}$ & 23 & & & \\
\hline 4 & $\begin{array}{c}\text { PROLONGED } \\
\text { LABOUR. }\end{array}$ & 10 & & & \\
\hline 5 & $\begin{array}{c}\text { GRAND } \\
\text { MULITIPARA. }\end{array}$ & 8 & & & \\
\hline 6 & $\begin{array}{c}\text { MULTIPLE } \\
\text { GESTATION. }\end{array}$ & 26 & & & \\
\hline
\end{tabular}




\begin{tabular}{|c|c|c|c|}
\hline S.NO & CAUSE F PPH & $\begin{array}{l}\text { NO OF } \\
\text { CASES }\end{array}$ & FREQUENCY.(f/n $\} \times 100$. \\
\hline 1 & $\begin{array}{c}\text { MULTIPLE } \\
\text { PREGNANCY. }\end{array}$ & 26 & .2 \\
\hline 2 & ANEMIA. & 35 & .3 \\
\hline 3 & PREECLAMPSIA. & 29 & .2 \\
\hline 4 & $\begin{array}{l}\text { OVERDISTENDED } \\
\text { UTERUS. }\end{array}$ & 23 & .2 \\
\hline 5 & $\begin{array}{c}\text { PROLNGED } \\
\text { LABUR. }\end{array}$ & 10 & .1 \\
\hline 6 & GRAND MULTIES. & 7 & .07 \\
\hline
\end{tabular}

\begin{tabular}{|l|c|c|c|}
\hline S.NO & TOTAL NO & NO OF PPH & SUCCESS \\
& OF PPH & CASE & PERCENTAGE \\
& & $\begin{array}{c}\text { CONTRLLED } \\
\text { WITH FOLEY }\end{array}$ & \\
\hline 1 & 145 & 131 & $90.34 \%$ \\
\hline
\end{tabular}

\section{CONCLUSION}

Despite of the small study sample, the study concludes that the use of intra uterine Foleys balloon tamponade as an effective means of controlling massive obstetrical hemorrhage due to uterine atony (postpartum and post caesarean cases). It is safe, easily available, inexpensive, minimally invasive, does not require anesthesia, easy to use and can be performed by any level of health personnel with some training. The efficacy of the intra uterine balloon catheter tampnade for the treatment for $\mathrm{PPH}$ appears similar to other forms of management. In a systematic review of various conservative management modalities for this condition, estimated cumulative outcomes showed success rate of $90.34 \%$. Nevertheless the authors commented that balloon tamponade was the least invasive and most rapidly implemented and that it seemed logical to use it as the first step of management in suitable cases. 